\title{
Lignocellulose conversion for biofuel: a new pretreatment greatly improves downstream biocatalytic hydrolysis of various lignocellulosic materials
}

\author{
Seung Gon Wi ${ }^{1+}$, Eun Jin Cho ${ }^{1 \dagger}$, Dae-Seok Lee ${ }^{1}$, Soo Jung Lee ${ }^{1}$, Young Ju Lee ${ }^{2}$ and Hyeun-Jong Bae ${ }^{1,3^{*}}$
}

\begin{abstract}
Background: Lignocellulosic biomass is an attractive renewable resource for future liquid transport fuel. Efficient and cost-effective production of bioethanol from lignocellulosic biomass depends on the development of a suitable pretreatment system. The aim of this study is to investigate a new pretreatment method that is highly efficient and effective for downstream biocatalytic hydrolysis of various lignocellulosic biomass materials, which can accelerate bioethanol commercialization.

Results: The optimal conditions for the hydrogen peroxide-acetic acid (HPAC) pretreatment were $80^{\circ} \mathrm{C}, 2 \mathrm{~h}$, and an equal volume mixture of $\mathrm{H}_{2} \mathrm{O}_{2}$ and $\mathrm{CH}_{3} \mathrm{COOH}$. Compared to organo-solvent pretreatment under the same conditions, the HPAC pretreatment was more effective at increasing enzymatic digestibility. After HPAC treatment, the composition of the recovered solid was $74.0 \%$ cellulose, $20.0 \%$ hemicelluloses, and $0.9 \%$ lignin. Notably, $97.2 \%$ of the lignin was removed with HPAC pretreatment. Fermentation of the hydrolyzates by $\mathrm{S}$. cerevisiae resulted in $412 \mathrm{~mL}$ ethanol $\mathrm{kg}^{-1}$ of biomass after $24 \mathrm{~h}$, which was equivalent to $85.0 \%$ of the maximum theoretical yield (based on the amount of glucose in the raw material).

Conclusion: The newly developed HPAC pretreatment was highly effective for removing lignin from lignocellulosic cell walls, resulting in enhanced enzymatic accessibility of the substrate and more efficient cellulose hydrolysis. This pretreatment produced less amounts of fermentative inhibitory compounds. In addition, HPAC pretreatment enables year-round operations, maximizing utilization of lignocellulosic biomass from various plant sources.
\end{abstract}

Keywords: Bioethanol, Lignocellulosic biomass, Pretreatment, Energy efficiency

\section{Background}

The use of lignocellulosic bioenergy can reduce fossil fuel dependence and greenhouse gas emissions [1-3]. The largest proportion of petroleum consumption is for transportation, and bioenergy is clearly the only sustainable, low-cost, large-scale fuel production option [4-7]. However, producing bioethanol from lignocelluloses has limitations, given the inherent inefficiency of

\footnotetext{
*Correspondence: baehj@chonnam.ac.kr

${ }^{\dagger}$ Seung Gon Wi and Eun Jin Cho contributed equally

${ }^{3}$ Department of Bioenergy Science and Technology, Chonnam National

University, Gwangju 500-757, Republic of Korea

Full list of author information is available at the end of the article
}

extracting lignin, a highly recalcitrant lignocellulosic cell wall polymer, under mild conditions and with minimal loss of polysaccharides $[8,9]$. The success of lignocellulosic bioethanol will depend on the development of simple pretreatment technologies that effectively delignify a diverse portfolio of lignocellulosic biomass feedstocks. Reducing the enzyme cost while enhancing cellulose hydrolysis efficiency is another important consideration when developing suitable pretreatment technologies [10-12].

The enzymatic hydrolysis of lignocellulosic biomass is influenced by several factors, including lignin and hemicelluloses contents, cellulose crystallinity, degree of 
polymerization, accessible surface area, and pore volume. However, lignin has been believed to be a major hindrance in enzymatic hydrolysis [13, 14]. Because lignin forms a physical barrier to restrict the acess of cellulases to the cellulose. Delignification increases cell wall porosity, rendering the biomass more amenable to enzymatic hydrolysis. Selective lignin removal can minimize cellulose degradation and thus enhance enzymatic hydrolysis [15-17].

Maximizing the utilization of lignocellulosic biomass materials from various plant sources through yearround operation is another important requirement for developing effective pretreatment technologies. Many herbaceous biomass crops become available only for a specific time in the year. In addition, even though lignocellulosic biomass can be supplied annually, most pretreatments have been optimized for a specific model biomass, which has challenged the effective use of other biomass sources [18-21]. As cell walls in biomass feedstocks differ in structure and chemical composition, one pretreatment method will not necessarily fit all applications. Therefore, developing a pretreatment technology that is effective over a wide range of biomass materials is important.

A variety of pretreatment methods have been applied for pretreating lignocellulosic biomass, but only a few of them seem to be promising. These pretreatment methods include steam explosion, ammonia fiber expansion (AFEX), dilute acid, and ionic-liquid pretreatment. Various pretreatment processes for lignocellulosic biomass, and their advantages and disadvantages are summarized in Table 1 [22-25]. An ideal pretreatment should be cheap, as much as removal lignin, effective for various lignocellulosic substrates, minimal glucan loss, and less inhibitor generation. Consequently, there is currently no single pretreatment technology that is potentially acceptable for the multiple biomass conversion.
In this study, we introduce a new pretreatment method that is more efficient and effective for downstream biocatalytic hydrolysis of various lignocellulosic materials, which will accelerate bioethanol commercialization. This developed hydrogen peroxide $\left(\mathrm{H}_{2} \mathrm{O}_{2}\right)$-acetic acid $\left(\mathrm{CH}_{3} \mathrm{COOH}\right)$ (HPAC) pretreatment highly removes lignin without the use of high temperatures or strong acids. It can be applied to multiple lignocellulosic materials, reduces enzyme loading and downstream enzymatic hydrolysis time, and lowers generation of fermentation inhibitors during the process. We propose that the HPAC is a highly effective pretreatment to bioconvert lignocellulosic biomass. We provide data from our work on lignin removal, enzymatic hydrolysis, and fermentation of various lignocellulosic biomass materials.

\section{Results and discussion}

\section{Features of the HPAC pretreatment}

Our integrated approach to the new HPAC pretreatment method is explained in Fig. 1. It is a simple procedure involving mixing $\mathrm{H}_{2} \mathrm{O}_{2}$ and $\mathrm{CH}_{3} \mathrm{COOH}$ to form a reagent that effectively removes lignin from lignocellulosic biomass through partial hydrolysis of lignin bonds. Pretreatment efficiency was evaluated based on observations of lignin removal, enzymatic hydrolysis, and fermentation of rice straw, pine wood, and oak wood.

\section{Optimal conditions}

To optimize the pretreatment conditions, we first measured the ratio of $\mathrm{H}_{2} \mathrm{O}_{2}$ to $\mathrm{CH}_{3} \mathrm{COOH}$. The selected volume ratios were 1:9, 2:8, 3:7, 4:6, 5:5, 6:4, 7:3, 8:2, and 9:1. An equal volume mixture (5:5) was most effective (Fig. 2a and Additional file 1: Figure S1).

Other important factors are reaction temperature and time [26]. To verify the importance of these factors, we investigated the optimum pretreatment conditions necessary for enhancing enzymatic hydrolysis. Experiments

Table 1 Summary of pretreatment methods

\begin{tabular}{|c|c|c|c|c|}
\hline Pretreatment methods & Conditions & Advantage & Disadvantage & Reference \\
\hline Steam explosion & $\begin{array}{l}1.3 \mathrm{Mpa} \\
190^{\circ} \mathrm{C} \\
15 \mathrm{~min}\end{array}$ & Hemicelluloses removal & $\begin{array}{l}\text { Acid catalyst needed } \\
\text { Formation of inhibitors }\end{array}$ & {$[22]$} \\
\hline AFEX & $\begin{array}{l}\text { Anhydrous ammonia } \\
60-100{ }^{\circ} \mathrm{C} \\
250-300 \text { psi }\end{array}$ & $\begin{array}{l}\text { Lignin removal } \\
\text { Cellulose decrystallization }\end{array}$ & High energy & {$[23]$} \\
\hline Dilute acids & $\begin{array}{l}\mathrm{HCl} / \mathrm{H}_{2} \mathrm{SO}_{4} \\
130-200^{\circ} \mathrm{C}\end{array}$ & Hemicelluloses removal & $\begin{array}{l}\text { Formation of inhibitors } \\
\text { Neutralization step }\end{array}$ & {$[24]$} \\
\hline Ionic-liquid & $\begin{array}{l}90-200^{\circ} \mathrm{C} \\
1-24 \mathrm{~h}\end{array}$ & Break-up cellulose crystalline & Expensive & {$[25]$} \\
\hline HPAC & $\begin{array}{l}\mathrm{CH}_{3} \mathrm{COOH}: \mathrm{H}_{2} \mathrm{O}_{2} \\
80{ }^{\circ} \mathrm{C},<2 \mathrm{~h}\end{array}$ & Effectively lignin removal & Hemicellulose loss & Present work \\
\hline
\end{tabular}




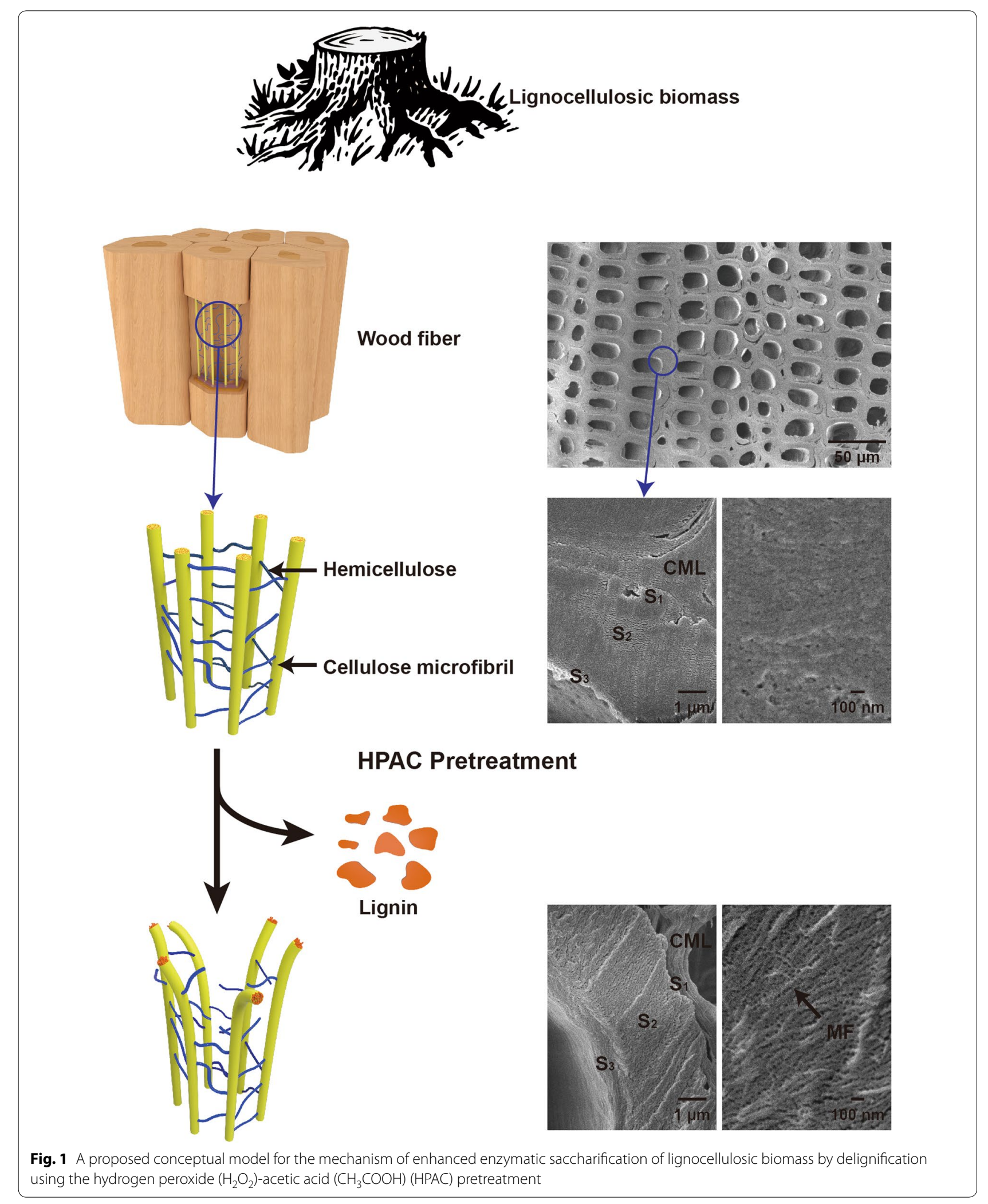



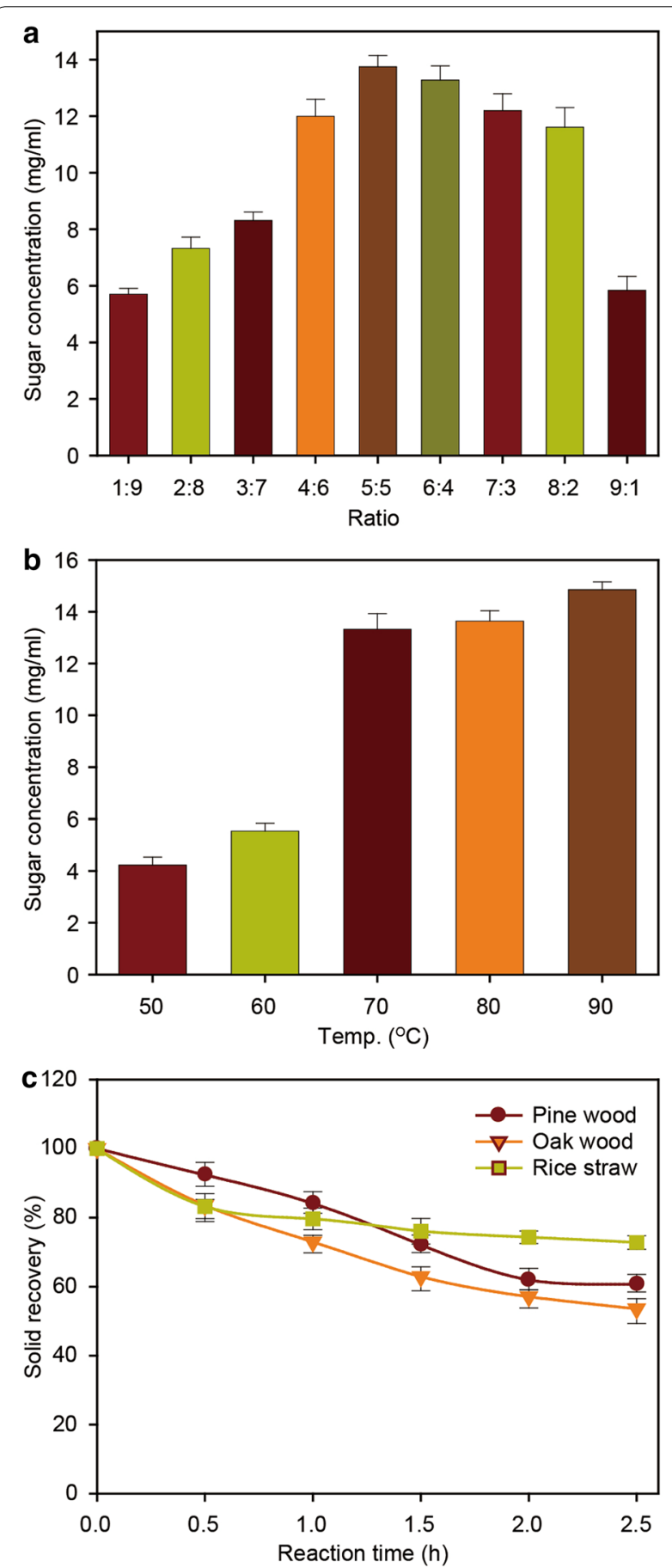

Fig. 2 a Effect of different volume ratios of hydrogen peroxide/ acetic acid. (Conditions: temperature, $80^{\circ} \mathrm{C}$; time, 2 h) b Effects of temperature on relative conversion to sugars. (Substrate: pine wood, Conditions: volume ratio of hydrogen peroxide/acetic acid, 5:5; time, $2 \mathrm{~h})$ c Solid recovery after the HPAC pretreatment

were done to investigate their effects on pretreatment by fixing the volume ratio of $\mathrm{H}_{2} \mathrm{O}_{2}$ and $\mathrm{CH}_{3} \mathrm{COOH}$ at 5:5. The effects of temperature and time on cellulose content are shown in Fig. 2b, c. Optimal pretreatment conditions for all three biomass materials were a temperature of $80{ }^{\circ} \mathrm{C}$ and a treatment time of $2 \mathrm{~h}$, which gave a high yield of total sugars (Fig. $2 \mathrm{~b}$ and Additional file 2: Figure S2). Generally, a longer pretreatment time and higher temperature increase delignification efficiency; however, these conditions use more energy, which is also an important factor to consider [27]. The acid pretreatment is usually carried out at high temperature, which causes metal corrosion, and this is also an important consideration when designing pretreatment reactors [28].

We also investigated total solid recovery after pretreatment. As expected, the recovery of solids decreased with increasing pretreatment time (Fig. 2c). Total recovery of solids after $2 \mathrm{~h}$ pretreatment was 58.8-75.2\%, based on the initial biomass weight. The decrease in water-insoluble solids (WIS) was mainly due to solubilization of hemicelluloses and lignin-derived compounds. Therefore, the optimal conditions for the HPAC pretreatment were $80{ }^{\circ} \mathrm{C}, 2 \mathrm{~h}$, and an equal volume mixture of $\mathrm{H}_{2} \mathrm{O}_{2}$ and $\mathrm{CH}_{3} \mathrm{COOH}$.

\section{Comparison to other pretreatments under the same conditions}

Previous studies on organo-solvent pretreatments have shown that the enzymatic digestibility of hydrogen peroxide [29, 30], acetic acid [31], peracetic acid (PAA, $\mathrm{CH}_{3} \mathrm{CO}_{3} \mathrm{H}$ ) [17], and $\mathrm{H}_{2} \mathrm{O}_{2}-\mathrm{CH}_{3} \mathrm{COOH}$ mixture effectively increases in the presence of catalysts such as sulfuric acid $\left(\mathrm{H}_{2} \mathrm{SO}_{4}\right)$ [32, 33], titanium dioxide $\left(\mathrm{TiO}_{2}\right)$ [34, 35], and sodium molybdate $\left(\mathrm{Na}_{2} \mathrm{MoO}_{4}\right)$ [36]. Therefore, we tested different solvent conditions, such as those with $\mathrm{CH}_{3} \mathrm{COOH}, \mathrm{H}_{2} \mathrm{O}_{2}, \mathrm{CH}_{3} \mathrm{CO}_{3} \mathrm{H}$, and a $\mathrm{CH}_{3} \mathrm{CO}_{3} \mathrm{H} / \mathrm{H}_{2} \mathrm{O}_{2}$ mixture. Compared to organo-solvent pretreatment under the same conditions, the HPAC pretreatment was more effective at increasing enzymatic digestibility (Fig. 3a). In addition, compared to a mechanical pretreatment (milling) and pretreatment with another acid $\left(\mathrm{H}_{2} \mathrm{SO}_{4}\right)$, the HPAC pretreatment was more effective at converting all three biomass materials into glucose (Fig. 3b). Moreover, when a mixture of three lignocellulosic materials was treated, the HPAC pretreatment was very effective at increasing enzymatic digestibility (Fig. 3b). These results indicate that HPAC pretreatment is a highly efficient and effective process for converting lignocellulosic materials into fermentable sugars.

\section{Changes in chemical composition during pretreatment}

A key question that we investigated was why the HPAC pretreatment is more effective than other processes. We reasoned that the main effect of HPAC pretreatment may be complete or nearly complete removal of lignin from 

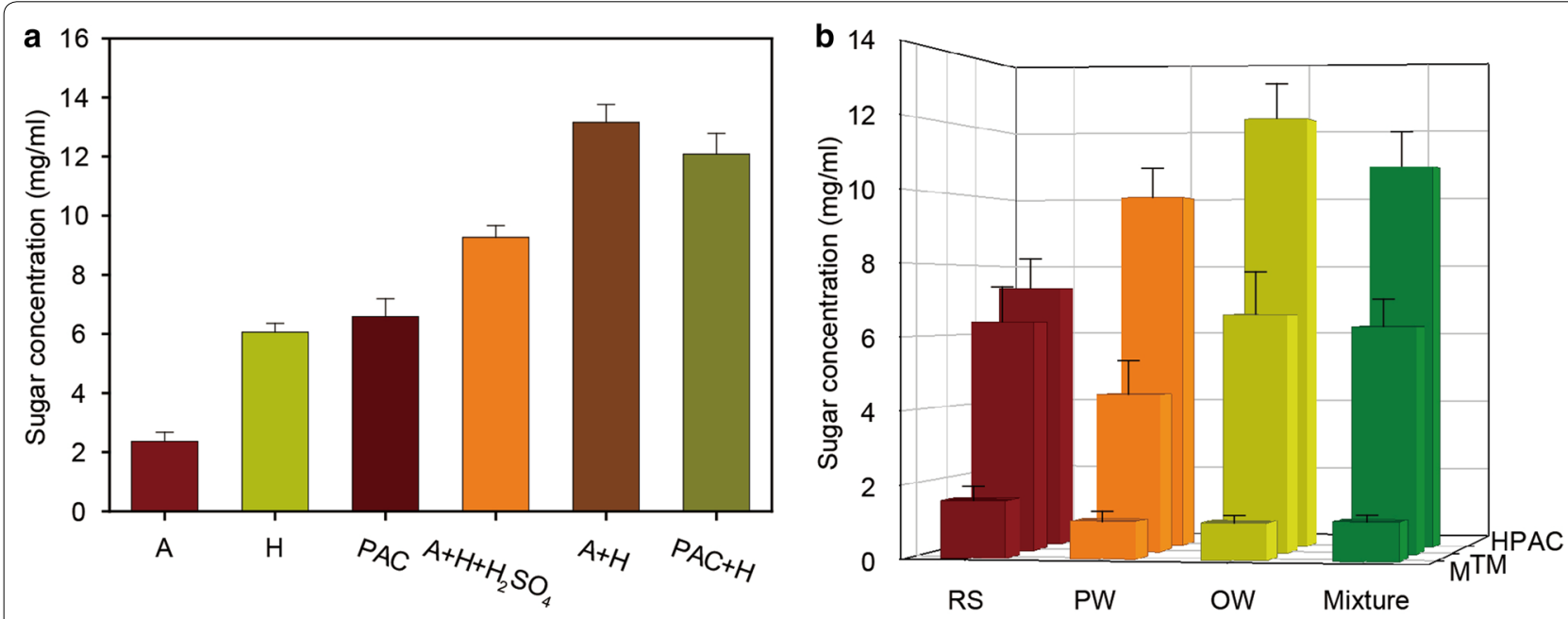

Fig. 3 a Effects of different organo-solvent pretreatments on enzymatic hydrolysis of pine wood. (A acetic acid, $H$ hydrogen peroxide, $P A C$ peracetic acid). $\mathbf{b}$ Influence of different pretreatment methods on sugar yields (RS rice straw, PW pine wood, OW oak wood)

the lignocellulosic biomass, leading to greatly improved enzymatic efficiency. The lignin in lignocellulosic cell walls restricts access of cellulase to cellulose, blocks progression of cleavage of cellulose chains by cellulases, and binds non-productively with cellulases, resulting in wasted enzymes. Lignin content and composition were analyzed to understand the impact of the HPAC pretreatment on delignification.

The compositions of the main chemical constituents in the three different biomass materials are provided in Additional file 3: Figure S3 and highlight the compositional differences in the feedstocks before and after HPAC pretreatment. All compositions were calculated based on the dry sample weight. The most significant compositional change was in lignin. The HPAC process removed $98.08 \%$ of the acid-insoluble lignin from the pine wood feedstock. Lignin content decreased by 97.61 and $85.12 \%$ in oak wood and rice straw, respectively. A relative increase in cellulose content was observed, compared to the initial raw material, due to the removal of other constituents such as lignin and ash. The low feedstock quality of rice straw was primarily due to its high ash and silica content compared to wood.

The yields of different reducing sugars, with respect to the increased pretreatment time for pine wood, are shown in Additional file 4: Figure S4. Glucose content was maximum (93.4\%) after $2 \mathrm{~h}$ of pretreatment. Lignin content dropped markedly by $98 \%$ with an increase in pretreatment time to a maximum of $2 \mathrm{~h}$ (Additional file 5: Figure S5). Thus, the increased conversion of cellulose would lead to an increase in available sugar content in the hydrolyzate.

\section{Solid-state CP/MAS ${ }^{13} \mathrm{C}$ NMR analysis}

Solid-state magic angle spinning carbon-13 nuclear magnetic resonance (CP/MAS ${ }^{13} \mathrm{C}$ NMR) experiments were carried out on pine wood either pretreated with HPAC or not pretreated, to collect data on chemical composition. The spectra are shown in Fig. 4 and Additional file 6: Figure S6. The NMR resonances were assigned according to data from the literature [37-39]. The peaks at $\delta 61.9$ and $\delta 64.8 \mathrm{ppm}$ were assigned to the C-6 glucopyranosyl repeating units in cellulose. The cluster of resonances around the peaks at $\delta 72.2$ and $\delta 75.8 \mathrm{ppm}$ were assigned to $\mathrm{C}-2, \mathrm{C}-3$, and $\mathrm{C}-5$. The peaks at $\delta 84.4$ and $\delta 89.0 \mathrm{ppm}$ were attributed to $\mathrm{C}-4$, and the absorption peak at $\delta$ $105.0 \mathrm{ppm}$ was assigned to $\mathrm{C}-1$ of glucose in cellulose. The solid-state NMR of pretreated pine wood showed

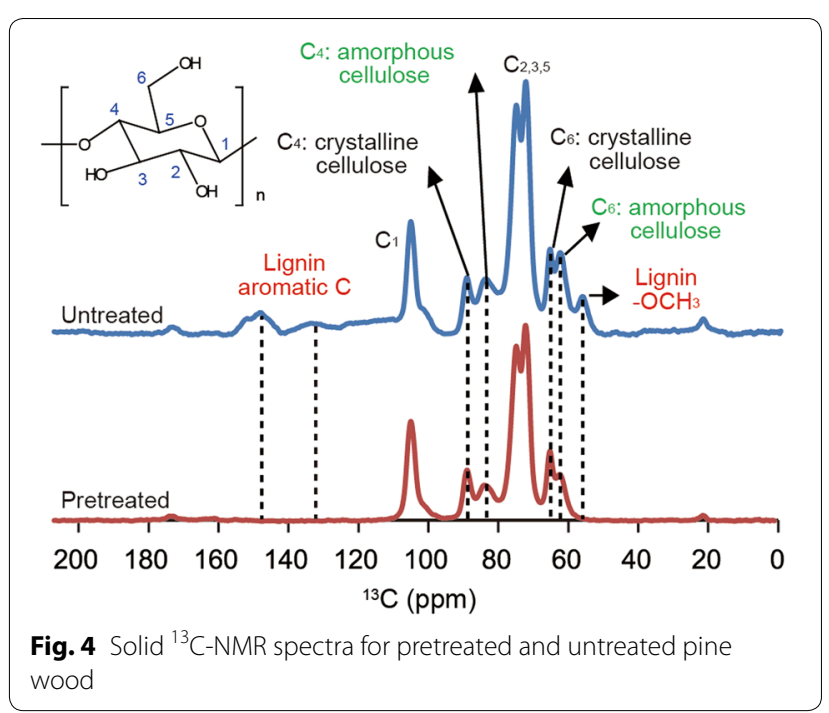


a decrease in signal intensities at both the C- 6 and C-4 peaks of amorphous cellulose, indicating preferential degradation of the amorphous regions during the pretreatment. In particular, signals at $\delta 56 \mathrm{ppm}$ and $\delta 130$ $155 \mathrm{ppm}$ were associated with the methoxyl and aromatic groups of lignin, respectively, demonstrating that the HPAC pretreatment removed all lignin components.

\section{Fourier transform-infrared (FT-IR) analysis}

FT-IR spectroscopy is frequently used to investigate the structure of constituents and the chemical changes in lignocellulosic biomass during pretreatment. Three representative chemical changes related to lignin removal based on the FT-IR analysis are shown in Additional file 7: Figure S7. The pretreated samples displayed significant decreases in band intensities at 1450 (C-H deformation), 1508 (aromatic skeletal vibrations), and $1640 \mathrm{~cm}^{-1}$ (conjugated $\mathrm{C}=\mathrm{O}$ stretch). This indicates that the HPAC pretreatment causes a breakdown of the aromatic structure of lignin.

\section{Lignin staining and brightness}

Microscopic observations also provided evidence of changes in lignocellulosic materials during the HPAC treatment. To confirm whether lignin was removed, we observed lignin by counterstaining with phloroglucinol, a reagent widely used to contrast lignified cell walls. Lignified cell walls acquire a bright red color with this stain. Sections from HPAC-treated material did not stain with phloroglucinol- $\mathrm{HCl}$, indicating the absence of lignin from cell walls (Additional file 8: Figure S8). This indicates that lignin content continues to decrease during HPAC treatment. Moreover, delignification of pine wood was further visually evaluated using a brightness analysis. Brightness improved by as much as $70.9 \%$ after HPAC pretreatment (Additional file 9: Figure S9), which was attributable to removing lignin. Lignin is the main source of color in pulp, as a variety of chromophores are naturally present in wood.

\section{Morphological changes in biomass from HPAC pretreatment}

The physical structure of biomass changes naturally after pretreatment, which can further affect enzymatic hydrolysis. Scanning electron microscopic (SEM) micrographs of pretreated and untreated pine wood were taken to study the changes in surface characteristics of the biomass. The SEM images clearly showed that untreated pine wood had a smooth and continuous surface. However, pores were present in the pretreated wood, which may have been due to high levels of removed residual lignin (Additional file 10: Figure S10). Moreover, cellulose fibrils appeared to have separated, suggesting enhanced enzymatic accessibility to cellulose. Similar results were obtained for oak wood and rice straw. These results indicate that HPAC pretreatment induces severe morphological changes in the plant cell walls studied and are in general agreement with significant lignin removal observed.

\section{Simultaneous saccharification and fermentation (SSF)}

The SSF process is one of the most promising processes for the production of ethanol from lignocellulosic biomass. The SSF process is carried out at faster rates, higher yields, and greater ethanol concentrations than is possible for the separate hydrolysis and fermentation (SHF) [40]. Thus, the productivity of ethanol was investigated by SSF of the three pretreated biomass materials to evaluate the efficiency of the HPAC pretreatment. Saccharification was achieved using crude cellulase and fermentation for $24 \mathrm{~h}$ by Saccharomyces cerevisiae, which were cultured at very near their optimum temperature $\left(37^{\circ} \mathrm{C}\right)$ with $10 \mathrm{FPU}$ cellulase $\mathrm{g}^{-1}$ biomass and 20 IU xylanase $\mathrm{g}^{-1}$ biomass (Fig. 5a). The ethanol concentration in HPAC-pretreated pine wood reached $0.325 \mathrm{~g} / \mathrm{g}$ biomass, based on enzymatic hydrolysis, assuming $87 \%$ fermentation yield within a $24-\mathrm{h}$ period $(1.32 \mathrm{~g}$ ethanol $/ 3.50 \mathrm{~g}$ glucose). Ethanol yields from pine wood and rice straw were 84 and $86 \%$ of the theoretically expected values, respectively.

Glucose and xylose production and the conversion to ethanol depending on pretreatment and SSF time are shown in Fig. 5b and Additional files 11, 12: Figures S11, S12. Most of the glucose and xylose were released within $24 \mathrm{~h}$. Glucose was converted into ethanol as quickly as it was produced, and most of the glucose produced was converted into ethanol within $24 \mathrm{~h}$. However, xylose-toethanol conversion did not occur, because $S$. cerevisiae cannot ferment xylose into ethanol.

\section{Light micrographs after enzymatic hydrolysis}

The effects of enzymatic hydrolysis on pine wood were further visually evaluated using light micrographs. After $24 \mathrm{~h}$ of enzymatic hydrolysis, pine cell walls were not observed in the cell wall structure (Additional file 13: Figure S13). These results could be explained, as least in part, by the extensive lignin removal during pretreatment, which increased enzyme accessibility to cellulose. In addition, the higher ethanol yield from the pretreated material was due to the increased quantities of reducing sugars in the fermenting medium.

\section{Inhibitor analysis}

One of the disadvantages of acid pretreatment is the formation of inhibitory compounds. The mild conditions of the HPAC pretreatment reduced 

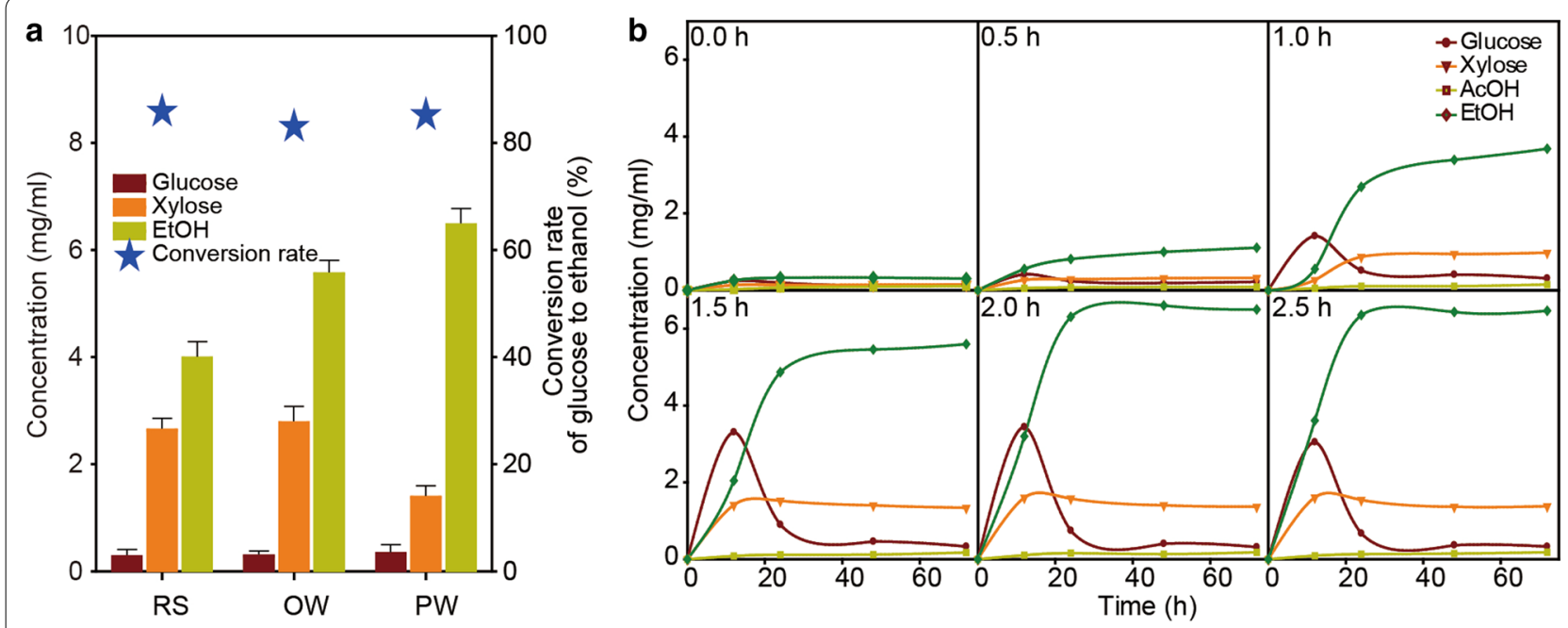

Fig. 5 a Conversion rate of glucose to ethanol and the concentrations of sugars and ethanol. b Time course of sugar utilization and ethanol production by Saccharomyces cerevisiae from hydrolyzate using an enzyme mixture containing cellulase (10 FPU/g DM) and xylanase (20 IU/g DM) after the HPAC pretreatment. Note: $a 0 \mathrm{~h}, b 0.5 \mathrm{~h}, \mathrm{c} 1.0 \mathrm{~h}, \mathrm{~d} 1.5 \mathrm{~h}, \mathrm{e} 2.0 \mathrm{~h}$, and $f 2.5 \mathrm{~h}$ of HPAC pretreatment time

degradation of monosaccharides into furfural and 5-hydroxymethylfurfural (HMF), which are very toxic to fermenting organisms. We confirmed that no inhibitors existed in pretreated solid residues using high-performance liquid chromatography (Additional file 14: Figure S14). Effective removal of inhibitory compounds would allow the use of more severe pretreatment conditions, which can improve sugar yields and lead to more efficient fermentation.

\section{Overall mass balance}

Using compositional analyses after each step, we created an overall mass balance for our operation, including the HPAC pretreatment and SSF steps (Fig. 6). The experiment used $5.25 \mathrm{~kg}$ of $\mathrm{CH}_{3} \mathrm{COOH}$ and $5.65 \mathrm{~kg}$ of $\mathrm{H}_{2} \mathrm{O}_{2} \mathrm{~g}^{-1}$ for pine wood $\left(1: 6\right.$ ratio of pine wood to solution at $80^{\circ} \mathrm{C}$ for $2 \mathrm{~h}$ ) for the pretreatment. After HPAC treatment, the composition of the recovered solid was $74.0 \%$ cellulose, $20.0 \%$ hemicelluloses, and $0.9 \%$ lignin. The total amount of hemicelluloses expressed as sum of xylose, mannose, and arabinose. Notably, $97.2 \%$ of the lignin was removed with HPAC pretreatment. After pretreatment, a substrate loading of $20 \%(\mathrm{w} / \mathrm{v})$ was chosen due to the well-known limiting effect of elevated substrate loading for SSF. Fermentation of the hydrolyzates by $S$. cerevisiae resulted in $412 \mathrm{~mL}$ ethanol kg-1 of biomass after $24 \mathrm{~h}$, which was equivalent to $85.0 \%$ of the maximum theoretical yield (based on the amount of glucose in the raw material). These results suggest that the cost of ethanol production from lignocellulosic biomass can be significantly reduced, as high sugar yields can be obtained with low enzyme loading.

\section{Conclusion}

In summary, lignocellulosic cell walls are analogous to reinforced concrete, in which the steel rebar resembles cellulose and the concrete resembles the lignin matrix. Removing concrete from a reinforced concrete structure readily exposes and weakens the steel rebar. Similarly, delignification exposes the cellulose fibrils in cell walls, resulting in efficient enzymatic hydrolysis of cellulose. Highly effective removal of lignin by the HPAC pretreatment resulted in enhanced enzymatic accessibility of the substrate, leading to more efficient cellulose hydrolysis. Furthermore, the HPAC pretreatment led to less formation of fermentative inhibitory compounds. In addition, the HPAC pretreatment enables year-round operations to maximize the value of biomass feedstock supply chains. HPAC pretreatment of the three different types of lignocellulosic biomass materials (i.e., an herbaceous plant, a softwood, and a hardwood) greatly improved downstream saccharification and fermentation, which are important for obtaining a high yield of bioethanol. In conclusion, our new HPAC pretreatment method will contribute to more effective bioethanol production from a wide variety of lignocellulosic biomass materials, with the added benefit of year-round application.

\section{Methods}

\section{Materials}

Hydrogen peroxide, acetic acid, and sulfuric acid were purchased from Duksan Chemicals Co. (Seoul, Korea). Bio-Rad reagent for protein assay was obtained from BioRad Laboratories (Hercules, CA, USA). The water used throughout this study was de-ionized and filtered using 


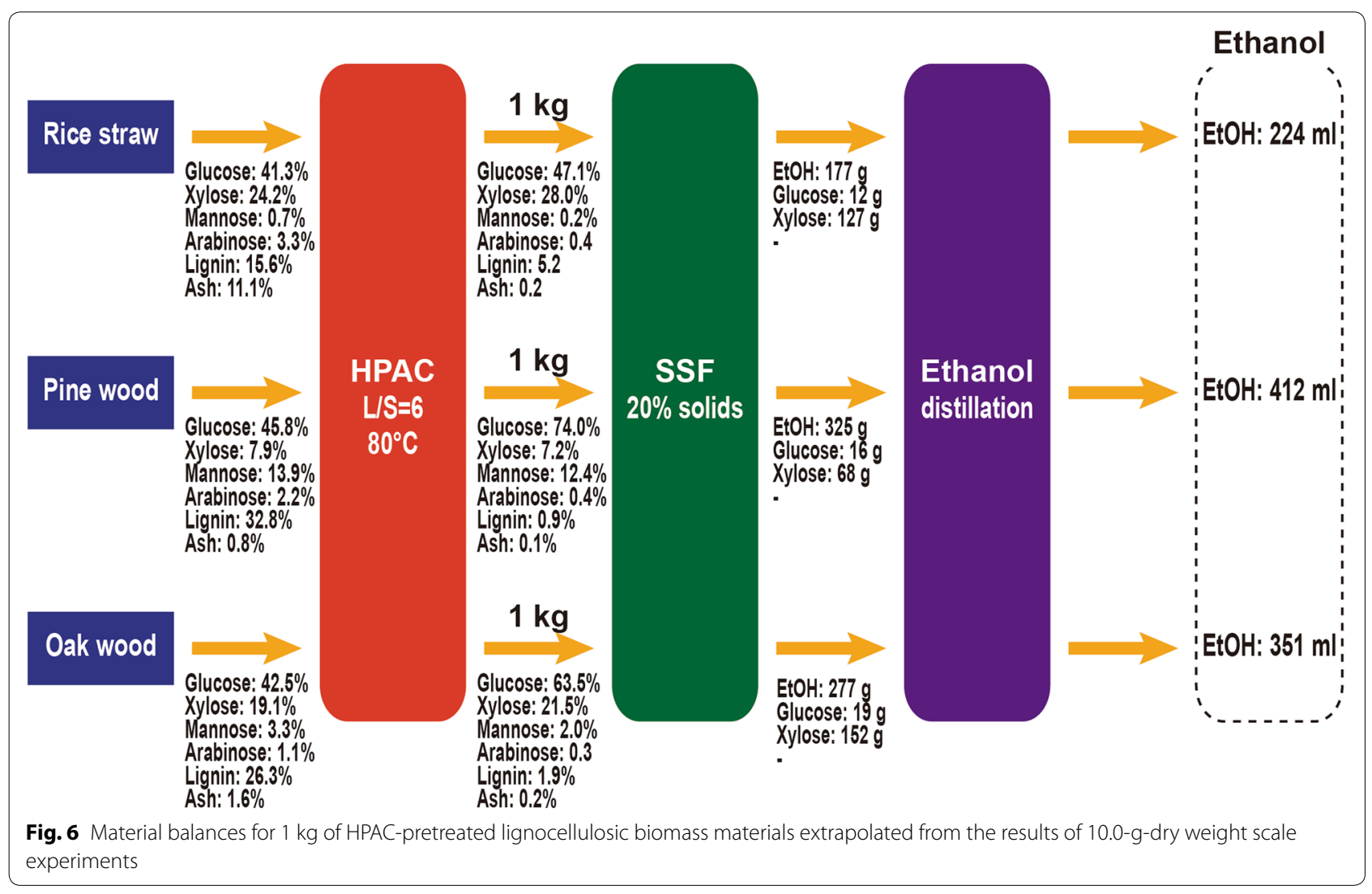

a US. Filter purification system. Oak wood and pine wood were obtained from a field in Chonnam National University, South Korea. Rice straw was obtained from a field in Mooan, South Korea, after being harvested for air dried at ambient temperature to equilibrium moisture content. The dried biomass were chopped into small pieces of $\sim 2 \mathrm{~cm}$ in length with a cutter, ground with a wet-disk mill (particle size: $0.7 \pm 0.2 \mathrm{~cm}$ ) and stored for pretreatment.

\section{HPAC (hydrogen peroxide-acetic acid) pretreatment}

The solution was prepared by mixing hydrogen peroxide and acetic acid $(1: 1 ; \mathrm{v} / \mathrm{v})$. Ten grams each of the cellulosic wastes was treated separately with $100 \mathrm{~mL}$ of the reagent and kept at $80^{\circ} \mathrm{C}$ for $2 \mathrm{~h}$. After pretreatment, the reaction was carried out in a thermostatic water bath. The residues were collected and washed extensively with distilled water until neutral $\mathrm{pH}$ was reached, filtered, and dried at room temperature for 2 days.

- Ratios of hydrogen peroxide/acetic acid: 1:9, 2:8, 3:7, 4:6, 5:5, 6:4, 7:3, 8:2, and 9:1 (v/v)

- Temperature: $50,60,70,80$ and $90^{\circ} \mathrm{C}$

- Reaction time: 30, 60, 90, 120, and 150 min. Reaction time was started after sample s reached the desired temperature.

\section{Chemical composition analysis}

After pretreatment, the biomass slurries were filtrated through $\operatorname{Kimax}^{\mathrm{TM}}$ Gooch 30-mL filtering crucibles, and the solid residue (WIS: water-insoluble solids) and WSF (watersoluble fraction) were separated. The WIS was subjected to enzymatic hydrolysis and the composition of WIS was analyzed. The chemical composition of holocellulose, lignin, organic solvent extractives and ash was analyzed using TAPPI Standard Methods [41]. Analyses of structural sugars (glucose, xylose, arabinose, mannose, galactose, and rhamnose) were conducted using a gas chromatograph [42].

\section{Histochemical analysis of lignin}

Lignin was stained with Wiesner reagents where phloroglucinol in acidic conditions gives a red-pink product with mainly the cinnamaldehyde groups present in lignins. Fresh sections were left for 5 min in $2 \%$ phloroglucinol in $95 \%$ ethanol and mounted in $6 \mathrm{~N} \mathrm{HCl}$.

\section{Enzymatic hydrolysis of pretreated substrates}

Enzymatic hydrolysis of WIS from pine wood, oak wood, and rice straw was carried out $2 \%$ substrate consistency ( $2 \mathrm{~g}$ biomass per each $100 \mathrm{~mL}$ solution, $10 \mathrm{mM}$ of sodium acetate buffer, pH 5.0) and $37^{\circ} \mathrm{C}$. The commercial enzymes used in this study were cellulase from Trichoderma longibrachiatum (C9748, Sigma-Aldrich) and xylanase from 
Trichoderma longibrachiatum (X2629, Sigma-Aldrich). Filter paper unit activity of cellulase was measured in terms of $\mathrm{FPU} / \mathrm{mL}$ [43]. One filter paper unit (FPU) was defined as the amount of enzyme required to release $1 \mu \mathrm{mol}$ of glucose from filter paper per min. Xylanase activity was measured on the basis of xylose released from birch wood xylan as a substrate and was expressed in terms of international units $(\mathrm{IU}) / \mathrm{mL}$. One IU was defined as the amount of enzyme required to release $1 \mu \mathrm{mol}$ of xylose from birch wood xylan per min [44]. The activities of cellulase and xylanase were $79 \mathrm{kFP} \mathrm{U} / \mathrm{mL}$ and $592 \mathrm{IU} / \mathrm{mL}$, respectively. Hydrolysate samples were collected at different time intervals during $24 \mathrm{~h}$. Reducing sugar were measured using a 3,5-dinitrosalicylic acid reagent and a standard glucose curve [45].

\section{Simultaneous saccharification and fermentation (SSF)}

Simultaneous saccharification and fermentation were conducted for pretreated materials in a $5-\mathrm{mL}$ total volume containing $2 \%(\mathrm{w} / \mathrm{v})$ dry matter, cellulase (10 FPU/g mass), xylanase (20 IU/g mass), $5 \mathrm{mg}$ dry yeast (S. cerevisiae KCTC 7906), $0.1 \%(\mathrm{w} / \mathrm{v})$ yeast extract, $0.2 \%(\mathrm{w} / \mathrm{v})$ peptone, and $0.05 \mathrm{M}$ citrate buffer $(\mathrm{pH} 4.8)$ at $37^{\circ} \mathrm{C}$ for $24 \mathrm{~h}$ in a $15-\mathrm{mL}$ conical tube. All experiments were performed in triplicate, and ethanol yield was calculated on the basis of total glucose content in the pretreated materials by dividing the quantity of ethanol produced by the total amount of glucose.

\section{Analysis of sugars and degradation compounds}

During enzymatic hydrolysis and fermentation, sugars, ethanol, and degradation compound were monitored using HPLC equipped with a refractive index (RI) detector (Waters 2414, USA). A Rezex RPM column $(300 \times 7.8 \mathrm{~mm}$; Phenomenex, Torrance, CA $)$ was used for sugars (i.e., glucose, and xylose). HPLC-grade water was supplied at a flow rate of $0.6 \mathrm{~mL} / \mathrm{min}$ as a mobile phase at a controlled temperature of $85^{\circ} \mathrm{C}$. Also, a Rezex ROA organic acid column $(300 \times 7.8 \mathrm{~mm}$; Phenomenex, Torrance, CA) was used for compound identification (i.e., ethanol, furfural, HMF, levulinic acid, and acetic acid). The temperatures of the column and detector were maintained at 65 and $40{ }^{\circ} \mathrm{C}$, respectively, and $5 \mathrm{mM}$ sulfuric acid was added to the mobile phase at a flow rate of $0.6 \mathrm{~mL}$ per min.

The total amount of lignin degradation compounds in WSF liquors was determined by the Folin-Ciocalteu method using phenol as a standard and reported as phenol equivalents (PE) $[46,47]$.

\section{Structural characterizations}

The surface morphologies of the samples were examined using field-emission scanning electron microscopy (FESEM) with a JSM-7500 F (Jeol, Japan) instrument operating at a beam voltage of $3 \mathrm{kV}$. Prior to observation, each sample was dehydrated with a graded ethanol series and freeze-dried. The external surface of the sample was then sputter-coated with osmium suing a sputter-coater. The FT-IR spectrum of the lyophilized sample was performed with the ATR technique using a PerkinElmer Spectrum 400. The spectrum was scanned in a range from 4000 to $400 \mathrm{~cm}^{-1}$ by 4 scans with a resolution of $4 \mathrm{~cm}^{-1}$. Solid-state ${ }^{13} \mathrm{C}$-NMR spectroscopy utilizing CP-MAS was performed using a Bruker DMX-400 MHz NMR spectrometer.

\section{Additional files}

Additional file 1: Figure S1. Effects of different volume ratios of hydrogen peroxide/acetic acid. (Conditions: temperature, $80^{\circ} \mathrm{C}$; time, $2 \mathrm{~h}$ ) A. Substrate: oak wood, B. Substrate: rice straw.

Additional file 2: Figure S2. Effects of temperature on relative conversion to sugars (Conditions: volume ratio of hydrogen peroxide/acetic acid, 5:5; time, 2 h). A. Substrate: oak wood, B. Substrate: rice straw.

Additional file 3: Figure S3. Chemical composition analysis of untreated and pretreated biomass (RS, untreated rice straw; Pre-RS, pretreated rice straw; OW, untreated oak wood; Pre-OW, pretreated oak wood; PW, untreated pine wood; and Pre-PW, pretreated pine wood). Values are percentages on a dry matter basis.

Additional file 4: Figure S4. Effects of pretreatment time on the yields of different reducing sugars. A. Substrate: pine wood, B. Substrate: oak wood, C. Substrate: rice straw.

Additional file 5: Figure S5. Effects of reaction time on lignin content. Additional file 6: Figure S6. Solid ${ }^{13} \mathrm{C}$-NMR spectra of pretreated and non-pretreated oak wood.

Additional file 7: Figure S7. FT-IR spectra of (A) oak wood and (B) pine wood.

Additional file 8: Figure S8. (A) Distribution of lignin in pretreated and untreated pine wood: (a) untreated pine wood, (b) untreated pine wood after phloroglucinol staining, (c) pretreated pine wood, (d) pretreated pine wood after phloroglucinol staining. (B) Distribution of lignin in pretreated and non-pretreated oak wood. (a) untreated oak wood, (b) untreated oak wood after phloroglucinol staining, (c) pretreated oak wood, (d) pretreated oak wood after phloroglucinol staining

Additional file 9: Figure S9. Effect of brightness on reaction time.

Additional file 10: Figure S10. (A) Scanning electron micrographs of treated and untreated pine wood. (a) Untreated pine wood at low magnification; (b) untreated pine wood at high magnification; (c) pretreated pine wood at low magnification; (d) pretreated pine wood at high magnification. (B) Scanning electron micrographs of treated and unpretreated oak wood and rice straw. (a) untreated oak wood, (b) untreated rice straw, (c) treated oak wood, (d) treated rice straw.

Additional file 11: Figure S11. Time course of sugar utilization and ethanol production by Saccharomyces cerevisiae from hydrolyzate using an enzyme mixture containing cellulase (10 FPU/g DM) and xylanase (20 IU/g DM) after the HPAC pretreatment. Note: (a) $0 \mathrm{~h}$, (b) $0.5 \mathrm{~h}$, (c) $1.0 \mathrm{~h}$, (d) $1.5 \mathrm{~h}$, (e) $2.0 \mathrm{~h}$, and (f) $2.5 \mathrm{~h}$ of HPAC pretreatment time. Substrate: oak wood.

Additional file 12: Figure S12. Time course of sugar utilization and ethanol production by Saccharomyces cerevisiae from hydrolyzate using an enzyme mixture containing cellulase (10 FPU/g DM) and xylanase (20 lU/g DM) after the HPAC pretreatment. Note: (a) 0 h, (b) 0.5 h, (c) $1.0 \mathrm{~h}$, (d) $1.5 \mathrm{~h}$, (e) $2.0 \mathrm{~h}$, and (f) $2.5 \mathrm{~h}$ of HPAC pretreatment time. Substrate: rice straw.

Additional file 13: Figure S13. Light micrographs of pretreated (A) pine wood and (B) oak wood. (a) before and (b) after saccharification.

Additional file 14: Figure S14. HPLC spectra of the simultaneous saccharification and fermentation (SSF) extracts. AA, acetic acid; Ff, Furfural; G1, glucose; G2, cellobiose; HMF, 5-hydroxymethylfurfural; SA, succinic acid; X1, xylose; Xt, xylitol. 


\section{Abbreviations}

HPAC: hydrogen peroxide-acetic acid; PAA: peracetic acid; NMR: nuclear magnetic resonance; FT-IR: Fourier transform-infrared; FE-SEM: field-emission scanning electron microscopy; SSF: Simultaneous saccharification and fermentation; S. cerevisiae: Saccharomyces cerevisiae; HPLC: high-performance liquid chromatography; HMF: 5-hydroxymethylfurfural; WIS: water-insoluble solids; WSF: water-soluble fraction; FPU: filter paper unit; IU: international units; $\mathrm{Rl}$ : refractive index; $\mathrm{RS}$ : rice straw; PW: pine wood; OW: oak wood.

\section{Authors' contributions}

SGW carried out the pretreatment, enzymatic hydrolysis, SEM, microscope, and ethanol fermentation analyses including the HPLC and helped draft and revise the manuscript. EJC performed the pretreatment and NMR analyses. EJC also drafted and revised the manuscript. DSL carried out the enzymatic hydrolysis and helped draft the manuscript. SJL carried out the FT-IR, chemical composition analyses and helped draft the manuscript. YJL carried out NMR analysis and helped draft the manuscript. HJB coordinated the study, contributed to the analysis of the results and in the improvement of the manuscript. All authors read and approved the final manuscript.

\section{Author details}

${ }^{1}$ Bio-Energy Research Center, Chonnam National University, Gwangju 500-757, Republic of Korea. ${ }^{2}$ Gwangju Center, Korea Basic Science Institute, Gwangju 500-757, Republic of Korea. ${ }^{3}$ Department of Bioenergy Science and Technology, Chonnam National University, Gwangju 500-757, Republic of Korea.

\section{Acknowledgements}

This work was supported by the Priority Research Centers Program through the National Research Foundation of Korea (NRF) (Project No. 2010-0020141) of the Ministry of Education, Science, and Technology of Korea. Also, this work was supported by the National Research Foundation of Korea (NRF) grant funded by the Korea government (MSIP) (No. 2015R1A2A2A01004594).

\section{Competing interests}

The authors declare that they have no competing interests.

Received: 15 September 2015 Accepted: 15 December 2015

Published online: 24 December 2015

\section{References}

1. Himmel ME, Ding SY, Johnson DK, Adney WS, Nimlos MR, Brady JW, Foust TD. Biomass recalcitrance: engineering plants and enzymes for biofuel production. Science. 2007;315:804-7.

2. Sanderson K. Lignocellulose: a chewy problem. Nature. 2011;474:ss2-4.

3. Barakat A, Monlau F, Solhy A, Carrere H. Mechanical dissociation and fragmentation of lignocellulosic biomass: effect of initial moisture, biochemical and structural properties on energy requirement. Appl Energ. 2015;142:240-6.

4. Lynd LR, Laser MS, Bransby D, Dale BE, Davison B, Himilton R, Himmel M, Keller M, McMillan JD, Sheehan J, Wyman CE. How biotech can transform biofuels. Nat Biotechnol. 2008;26:169-72.

5. Somerville C, Youngs H, Taylor C, Davis SC, Long SP. Feedstocks for lignocellulosic biofuels. Science. 2010;329:790-2.

6. Melero JA, Iglesias J, Garcia A. Biomass as renewable feedstock in standard refinery units. Feasibility, opportunities and challenges. Energy. Environ Sci. 2012;5:7393-420.

7. McAloon A, Taylor F, Yee W, Ibsen K, Wolley R. Determining the cost of producing ethanol from corn starch and lignocellulosic feedstocks. NREL/ TP-580-28893. Golden: National Renewable Energy Laboratory; 2000.

8. Limayem A, Ricke SC. Lignocellulosic biomass for bioethanol production: current perspectives, potential issues and future prospects. Prog Energ Combust Sci. 2012;38:449-67.

9. Brijwani K, Oberoi HS, Vadlani PV. Production of a cellulolytic enzyme system in mixed-culture solid-state fermentation of soybean hulls supplemented with wheat bran. Process Biochem. 2010;45:120-8.

10. Verardi A, De Bari l, Ricca E, Calabrò V. Hydrolysis of lignocellulosic biomass: current status of process and technologies and future perspectives. Intechopen; 2011. http://www.intechopen.com.
11. El-Naggar NEA, Deraz S, Khalil A. Bioethanol production from lignocellulosic feedstocks based on enzymatic hydrolysis: current status and recent developments. Biotechnology. 2014;13:1-21.

12. Wi SG, Choi IS, Kim KH, Kim HM, Bae H-J. Bioethanol production from rice straw by popping pretreatment. Biotechnol Biofuels. 2013;6:166-72.

13. Chang VS, Holtzapple MT. Fundamental factors affecting biomass enzymatic reactivity. Appl Biochem Biotechnol. 2000;84:5-37.

14. Kim TH, Kim JS, Sunwoo C, Lee YY. Pretreatment of corn stover by aquous ammonia. Bioresour Tech. 2003;90:39-47.

15. Barakat A, Chuetor S, Monlau F, Solhy A, Rouau X. Eco-friendly dry chemomechanical pretreatments of lignocellulosic biomass: impact on energy and yield of the enzymatic hydrolysis. Appl Energ. 2014;113:97-105.

16. Dekker RF. Enzymatic hydrolysis of plant polysaccharides: substrates for fermentation. Braz J Med Biol Res. 1989;22:1441-56.

17. Zhao X, Wang L, Liu D. Effect of several factors on peracetic acid pretreatment of sugarcane for enzymatic hydrolysis. J Chem Technol Biotechnol. 2007:82:1115-21.

18. Zheng Y, Zhao J, Xu F, Li Y. Pretreatment of lignocellulosic biomass for enhanced biogad production. Prog Energ Combust Sci. 2014;42:35-53.

19. Chiaramonti D, Prussi M, Ferrero S, Oriani L, Ottonello P, Torre P, Cherchi F. Review of pretreatment processes for lignocellulosic ethanol production, and development of an innovative method. Biomass Bioenerg. 2012;46:25-35.

20. Alvira P, Tomás-Pejó E, Ballesteros M, Negro MJ. Pretreatment technologies for an efficient bioethanol production process based on enzymatic hydrolysis: a review. Bioresour Technol. 2010;101:4851-61.

21. Zhao X, Cheng K, Liu D. Organosolv pretreatment of lignocellulosic biomass for enzymatic hydrolysis. Appl Microbiol Biotechnol. 2009;82:815-27.

22. Galbe M, Zacchi G. Pretreatment of lignocellulosic materials for efficient bioethanol production. Adv Biochem Eng Bioechnol. 2007;108:41-65.

23. Li C, Cheng G, Balan V, Kent MS, Ong M, Chundawat SP, Sousa LD, Melnichenko YB, Dale BE, Simmons BA, Singh S. Influence of physicochemical changes on enzymatic digestibility of ionic liquid and AFEX pretreated corn stover. Bioresour Technol. 2011;102:6928-36.

24. Agbor VB, Cicek N, Sparling R, Berlin A, Levin DB. Biomass pretreatment: fundamentals toward application. Biotechnol Adv 2011:29:675-85.

25. Espinoza-Acosta JL, Torres-Chávez PI, Carvajal-Millán E, Ramírez-Wong B, Bello-Pérez LA, Montaño-Leyva B. Ionic Liquids and Organic Solvents for Recovering Lignin from Lignocellulosic Biomass. Bioresources. 2014:9:3660-87.

26. Han L, Feng J, Zhang S, Ma Z, Wang Y, Zhang X. Alkali pretreatment of wheat straw and its enzymatic hydrolysis. Braz J Microbiol. 2012;43:53-61.

27. Taherzadeh MJ, Karimi K. Pretreatment of lignocellulosic wastes to improve ethanol and biogas production: a review. Int J Mol Sci. 2008;9:1621-51.

28. Teixeira LC, Linden JK, Schroeder HA. Alkaline and peracetic acid pretreatment of biomass for ethanol production. Appl Biochem Biotechnol. 1999;77:19-34.

29. Roy S, Kumar K, Ghosh S, Das D. Thermophilic biohydrogen production using pre-treated algal biomass as substrate. Biomass Bioenerg. 2014;61:157-66.

30. Jain A, Balasubramanian R, Srinivasan MP. Production of high surface area mesoporous activated carbons from waste biomass using hydrogen peroxide-mediated hydrothermal treatment for adsorption applications. Chem Eng J. 2015;273:622-9.

31. Vazquez G, Antorrena G, Gonzalez J, Freire S, Crespo I. The influence of acetosolv pulping conditions on the enzymatic hydrolysis of Eucalyptus pulps. Wood Sci Technol. 2000;34:345-54.

32. Tan H, Yang R, Sun W, Wang S. Peroxide-acetic acid pretreatment to remove bagasse lignin prior to enzymatic hydrolysis. Ind Eng Chem Res. 2010;49:1473-9.

33. Sun RC, Tomkinson J, Zhu W, Wang SQ. Delignification of maize stems by peroxymonosulfuric acid, peroxyformic acid, peracetic acid, and hydrogen peroxide. 1. Physicacochemical and structural characterization of the solubilized lignins. J Agric Food Chem. 2000;48:1253-62.

34. Kuznetsov BN, Kuznetsova SA, Danilov VG, Yatsenkova OV. Abies wood delignification by acetic acid-hydrogen peroxide mixture under the action of $\mathrm{TiO}_{2}$ catalysts and UV irradiation. J Sib Fed Univ Chem. 2009:1(1):19-24. 
35. Lanzalunga O, Bietti M. Photo- and radiation chemical induced degradation of lignin model compounds. J Photochem Photobiol B Biol. 2000;56:85-108.

36. Kuznetsov BN, Kuznetsova SA, Danilov VG, Kozlov IA, Taraban'ko VE, Ivanchenko NM, Alexandrova NB. New catalytic processes for a sustainable chemistry of cellulose production from wood biomass. Catal Today. 2002;75:211-7.

37. Matulova M, Nouaille R, Cappek P, Pe'an M, Forano E, Delort AM. Degradation of wheat straw by Fibrobacter succinogenes S85: a liquid- and solid-state nuclear magnetic resonance study. Appl Environ Microbiol. 2005;71:1247-53.

38. Locci E, Laconi S, Pompei R, Scano P, Lai A, Marincola FC. Wheat bran biodegradation by Pleurotus ostreatus: a solid-state carbon- ${ }^{13}$ NMR study. Bioresour Technol. 2006;99:4279-84.

39. Sannigrahi P, Ragauskas AJ, Miller SJ. Effects of two-stage dilute acid pretreatment on the structure and composition of lignin and cellulose in loblolly pine. Bioenergy Res. 2008;1:205-14.

40. Tomás-Pejó E, Oliva JM, Ballesteros M, Olsson L. Comparison of SHF and SSF processes from steam-exploded wheat straw for ethanol production by xylose-fermenting and robust glucose-fermenting Saccaromyces cerevisiae strains. Biotechnol Bioeng. 2008;100:1122-31.

41. TAPPI Committee. Tappi test methods. Atlanta: TAPPI Press; 1992.

42. Wi SG, Chung BY, Lee YG, Yang DJ, Bae H-J. Enhanced enzymatic hydrolysis of rapeseed straw by popping pretreatment for bioethanol production. Bioresour Technol. 2011;102:5788-93.

43. Adney B, Baker J. Measurement of cellulase activities. NREL/TP-510-42628. Golden: National Renewable Energy Laboratory; 2008.

44. Teixeira RSS, Siqueira FG, Souza MVD, Filho EXF, Bon EPDS. Purification and characterization studies of a thermostable $\beta$-xylanase from Aspergillus awamori. J Ind Microbiol Biotechnol. 2010;37:1041-51.

45. Miller GL. Use of dinitrosalicylic acid reagent for determination of reducing sugar. Anal Chem. 1959;31:426-8.

46. Lin SY, Dence CW. Methods in lignin chemistry. Springer series in wood science. Berlin: Springer-Verlag; 1992.

47. Boerjan W, Ralph J, Baucher M. Lignic biosynthesis. Annu Rev Plant Biol. 2003:54:519-46.

\section{Submit your next manuscript to BioMed Central and we will help you at every step:}

- We accept pre-submission inquiries

- Our selector tool helps you to find the most relevant journal

- We provide round the clock customer support

- Convenient online submission

- Thorough peer review

- Inclusion in PubMed and all major indexing services

- Maximum visibility for your research

Submit your manuscript at www.biomedcentral.com/submit
() BioMed Central 